\title{
Merebut Paus di Laut Sawu: \\ Konflik Kepentingan Konservasi Paus antara Negara dan Masyarakat Lamalera, Nusa Tenggara Timur1
}

\author{
Agustinus Gergorius Raja Dasion 2 \\ Abstraksi
}

Penelitian ini menggunakan metode kualitatif, dengan kerangka teoritis wacana Laclau dan Mouffe. Analisa ini bertujuan untuk melihat seluruh praktik sosial yang dilakukan oleh negara dan masyarakat terkait wacana konservasi paus di Laut Sawu, NTT. Hasil penelitian menunjukan bahwa konflik antara masyarakat Lamalera dengan negara terjadi sejak tahun 2001. Konflik itu terkait wacana konservasi Laut Sawu yang secara langsung membatasi wilayah melaut masyarakat Lamalera. Wacana konservasi dimulai dengan pembentukan Kawasan Konservasi Laut Daerah Solor-Lembata-Alor (KKLD-Solar) di tahun 2006. Negara berusaha membangun kesadaran masyarakat lewat berbagai seminar, sosialisasi, dan program Dinas Pariwisata dan Ekonomi Kreatif Provinsi Nusa Tenggara Timur. Masyarakat lokal merasa terusik dan berusaha menolak rencana konservasi tersebut. Mereka menilai bahwa perburuan paus yang mereka lakukan sejak dahulu, selalu mematuhi aturanaturan adat lokal, dengan menerapkan pengetahuan tradisional tentang konservasi kehidupan laut.

Kata kunci: konservasi paus, masyarakat adat, konflik kepentingan, analisis wacana, Nusa Tenggara Timur (NTT)

\begin{abstract}
This study employs qualitative method with reference to Laclau and Mouffes' discourse analysis. The analysis aims to examine social practices carried out by the state and society in responding the whale conservation discourse in the Sawu Sea, East Nusa Tenggara (NTT). The result of the study shows that conflict between the Lamalera people and the state has been occurred since 2001. This conflict responds to the Sawu Sea conservation discourse that affected on the limitation of the Lamalera community's sea fishing area. The conservation discourse began with the establishment of the Solor-Lembata-Alor Regional Marine Conservation Area (KKLDSolar) in 2006. The state seeks to disseminate public awareness through various seminars, socialization, and the tourism program sponsored by the Department of Tourism and Creative Economy of East Nusa Tenggara Province. Local people feel disturbed and try to reject the conservation plan. They considered that the whaling (whale hunting) is a part of their obedience towards prolonged respected local customary law, given the fact that they are still hold their own traditional knowledge for sealife conservation.
\end{abstract}

Keywords: whale conservation, customary society, conflict of interest, discourse analysis, East Nusa Tenggara

\section{A. Pendahuluan}

Globalisasi selalu masif bergerak mempersatukan dunia. Mike Fatherstone (dalam Nugroho, 1997: 66), menjelaskan bahwa globalisasi diungkapkan sebagai "paradox of culture", dimana globalisasi akan mewujudkan suatu situasi di mana bangsa-bangsa di dunia menjadi satu dalam format "big village". Salah satu anak kandung globalisasi adalah kesadaran dan kekhawatiran yang semakin satu tentang berbagai kondisi alam. Dari berbagai kesadaran yang semakin satu, upaya konservasi ekologi, termasuk konservasi mamalia laut yakni ikan paus adalah salah satunya. Konservasi ekologi, khususnya paus hadir ketika mulai ada kesadaran manusia akan pentingnya keseimbangan ekosistem

\footnotetext{
${ }^{1}$ Untuk kutipan atau sitasi artikel ini: Agustinus Gergorius Raja Dasion. 2019. "Merebut Paus di Laut Sawu: Konflik Kepentingan Konservasi Paus antara Negara dan Masyarakat Lamalera, Nusa Tenggara Timur." Jurnal Pemikiran Sosiologi Vol 6 (2): 41-57

2 Program pascasarjana (S3) Sosiologi-Fisipol, Universitas Gadjah Mada. Kontak penulis: agustinus.dasion@yahoo.co.id
} 
Jurnal Pemikiran Sosiologi Volume 6 No.1 2019

Merebut Paus di Laut Sawu:

Konflik Kepentingan Konservasi Paus antara Negara dan Masyarakat Lamalera, Nusa Tenggara Timur Agustinus Gergorius Raja Dasion

alam. Ketika kesadaran tersebut semakin bersatu, hadir lembaga yang memiliki otoritas mengatur kesadaran tersebut. Akhirnya, kesadaran yang dibangun secara terus menerus bisa menjelma menjadi sebuah "kesatuan" kesadaran yang terkontrol. Foucault menyebutnya dalam konsepnya governmentalitas (Ettlinger, 2011: 539).

Namun di tengah berbagai usaha membangun kesadaran konservasi, masyarakat lokal yang hidupnya bergantung pada alam dengan berburu dan mengkonsumsi ikan paus, telah terlebih menerapkan upaya penjagaan (konservasi) atas sumber daya alam secara berkesinambungan. Cara berburu, pengolahan, juga pemanfaatan ikan paus berbasis lokal atau adat menjadi hal yang paling utama bagi masyarakat Lamaera (Nolin, 2010: 246). Dengan nilai-nilai lokal (local wisdom) yang selama ini mereka jalankan, upaya pemanfaatan alam dengan menjaga keberlangsungan hidup ekosistem bukanlah hal yang baru bagi masyarakat Lamalera.

Konflik besar antara masyarakat Lamalera dengan negara terjadi sejak tahun 2001. Konflik di atas terkait wacana konservasi Laut Sawu yang secara langsung membatasi wilayah melaut masyarakat Lamalera. Wacana perlindungan cetacean menjadi wacana baru di Indonesia, hingga mengemuka dengan pembentukan Kawasan Konservasi Laut Daerah Solor-Lembata-Alor (KKLDSolar). KKLD-Solar akhirnya ditetapkan secara resmi oleh SK Gubernur NTT di tahun 2006. Pada tahun 2010, CTI (Coral Triangel Initiative) dan Dinas Kelautan dan Perikanan (DKP)-RI mengeluarkan aturan Kawasan Konservasi Perairan (KKP) di Laut
Sawu dengan tiga zona konservasi. Zona kedua yang dikonservasi adalah tempat di mana masyarakat Lamalera berburu paus. Program dan sosialisasi lewat seminar terkait konservasi pun dilakukan secara bertahap hingga sekarang. Masyarakat merasa terusik dengan penetapan zona dua konservasi Laut Sawu yang pasti secara langsung berdampak pada keberlangsungan cara hidup masyarakat Lamalera.

Negara menjadi aktor pertama dalam membentuk kesadaran yang semakin besar akan pentingnya upaya konservasi paus. Di ranah lokal Lamalera, para ketua adat dan Gereja pun memiliki kuasa untuk membangun kesadaran masyarakat akan penggunaan sumber daya alam yang sesuai tradisi setempat. Sebagai aktor, mereka memiliki strategi untuk mencapai tujuan. Strategi tersebut muncul dalam bebagai wacana (praktik sosial) yang saling bersinggungan bahkan berusaha untuk saling menegasikan.

Ketika suatu wacana ditampilkan, muncul juga wacana baru sebagai upaya melawan wacana terdahulu. Wacana baru biasanya diciptakan sebagai upaya mempertegas eksistensi dan identitas sekelompok masyarakat. Wacana tidak hanya hadir lewat bahasa lisan atau tulisan. Wacana hadir dalam keseluruhan hidup masyarakat. Wacana yang dimaksud tidak hanya hadir dalam cerita atau teks tetapi dalam setiap praktik sosial (Haryatmoko, 2016:4).

Inilah yang dapat dijadikan dasar dalam melakukan penelitian tentang wacana konservasi paus di Laut Sawu, desa Lamalera, Lembata, Nusa Tenggara Timur. Peneliti menggunakan kata 
Jurnal Pemikiran Sosiologi Volume 6 No.1 2019

Merebut Paus di Laut Sawu:

Konflik Kepentingan Konservasi Paus antara Negara dan Masyarakat Lamalera, Nusa Tenggara Timur Agustinus Gergorius Raja Dasion

"merebut" untuk menjelaskan bagaimana wacana konservasi paus Lamalera dikonstruksikan secara berbeda antara negara dan masyarakat lokal Lamalera.

\section{B. Metode Penelitian dan Kerangka Analisa}

Metode kualitatif menjadi pilihan metode dalam studi ini. Studi kualitatif dianggap lebih cocok untuk dalam mengerti dan menganalisa setiap wacana yang adalah juga peristiwa, kisah, cerita dan perdebatan sosial. Untuk mencapai hasilnya, studi ini menggunakan pendekatan analisa wacana (discourse analysing) Laclau dan Mouffe. Analisa wacana ini dipilih dengan dua pertimbangan mendasar.

Pertama sebagai akademis, peneliti sendiri sudah menentukan analisis wacana sebagai posisi dalam melihat wacana dan tidak ingin memfokuskan studi dengan satu teks yang ditelaah hingga praktik sosialnya seperti yang dilakukan dalam metode Analisa Wacana Kritis atau Critical Discourse Analysis (CDA). Bagi peneliti, bahasa hanya merupakan salah satu elemen wacana yang hadir dalam praktik sosial. Wacana adalah praktik sosial. Wacana yang dimaksud adalah seluruh praktik sosial masyarakat Lamalera terkait wacana konservasi paus Lamalera.

Kedua, menurut Foucault, wacana merupakan sistem pengetahuan yang memberi informasi tentang teknologi sosial dan teknologi memerintah yang merupakan bentuk kekuasaan dalam masyarakat modern (Haryatmoko, 2016: 66). Dengan demikian wacana tidak bisa "hidup" sendiri tanpa tertuang dalam setiap praktik sosial masyarakat. Untuk itu, analisa wacana membatasi peneliti supaya tidak masuk dalam kajian teks atau ilmu linguistik sebagai titik awal melihat sebuah proses produksi makna wacana.

Teori diskursus Laclau dan Mouffe berasumsi bahwa semua obyek dan tindakan memiliki makna dan merupakan produk dari sistem-sistem partikular yang memiliki perbedaanperbedaan signifikan, yang bersifat spesifik secara historis (Hutagalung, 2008:11). Dengan demikian, makna dan proses wacana tidak bisa disimplifikasi lewat intensitas (keberulangan atau jumlah) diskursus sosial tetapi lebih dari itu bagaimana diskursus terkait konservasi dimaknai secara mendalam (dalam penciptaan wacana, dan praktik kekuasaan) oleh kedua belah pihak. The hidden atau beyond discourse menjadi titik tolak peneliti sehingga penelitian ini tidak timpang karena kesalahan metode.

Penelitian ini menggunakan data primer dan data sekunder. Data primer primer diperoleh lewat observasi dan wawancara terhadap enam informan kunci (key informants). Keenam informan kunci tersebut adalah:

a. Bapak Alo Gneser Tapoona (AGT/ penikam paus/ lamafa)

b. Bapak Nasu Seran Blikololong (NSB/ pembuat perahu/ ata mole)

c. Bapak Jefri Bataona (JB/ kepala suku Bataona dan kepala desa Lamalera)

d. Bapak. Uka Beding (UB/ Tua adat/ Ata mole)

e. Bona Beding (BB/ Aktivis Lingkar Aliansi Selamatkan Lamalera) 
Jurnal Pemikiran Sosiologi Volume 6 No.1 2019

Merebut Paus di Laut Sawu:

Konflik Kepentingan Konservasi Paus antara Negara dan Masyarakat Lamalera, Nusa Tenggara Timur Agustinus Gergorius Raja Dasion

f. Dr. Blajan Konradus, M.A. (BK/ Akademisi/ Antropolog Lamalera).

Data sekunder diperoleh lewat studi pustaka dan berbagai literatur, termasuk media massa, yang dapat membantu menjelaskan wacana konservasi di Laut Sawu.

Studi ini menggunakan tiga kerangka dasar yakni teori wacana, hegemoni dan governemntalitas. Konsep wacana menjadi penting dalam menjelaskan wacana koservasi yang tidak hanya hadir berupa teks tetapi hadir dalam seluruh praktik sosial masyarakat Lamalera. Kedua, konsep hegemoni menjelaskan bagaimana upaya masyarakat Lamalera dalam menanggapi wacana hegemonik konservasi global yang ditawarkan negara. Ketiga adalah konsep governmentalitas yang digunakan peneliti untuk melihat bagaimana upaya negara dalam membangun kesadaran masyarakat tentang wacana konservasi di Laut Sawu.

Teori wacana sebenarnya muncul sebagai upaya menjawab kelemahan paradigma penelitian ilmu sosial. Melalui kritik hermeneutis, teori wacana mengembangkan model interpretatif penelitian ilmu-ilmu sosial dan menolak pendekatan behavioral, rasional dan positivistik teori-teori dominan. Teori wacana mulai menemukan bentuknya yang "baru" ketika Foucault memperkenalkan tradisi analisanya dari arkeologi menuju genealogi. Sebenarnya teori ini sudah terlebih berkembang terlebih dahulu, namun fokus analisanya masih terbatas pada aspek semantis dari struktur bahasa. Foucault membuka ruang analisa baru ketika memperluas makna diskursus ke dalam area praktik sosial dengan memperjelas tautan kekuasaan yang hadir di dalamnya (Torfing: 1999: 1-9). Foucault menekankan bahwa semua praktik sosial bersifat diskursif atau kewacanaan. Hal ini berarti setiap praktik sosial dibentuk oleh aturan atau formasi diskursif yang akan terus berubahubah dalam ruang dan waktu. Hal ini juga berarti makna subuah tindakan sosial (termasuk pernyataan) tidak pernah ditemukan di luar wacana. Bagi Foucault, wacana adalah sistem pengetahuan yang memberi informasi tentang teknologi sosial dan teknologi memerintah yang merupakan bentuk kekuasaan dalam masyarakat modern. Wacana adalah praksis sosial dalam bentuk interaksi simbolis yang bisa terungkap dalam pembicaraan, tulisan, kial, gambar, diagram, film, atau music (N. Fairclough, 2010: 233).

Ciri dasar dari penggunaan teori ini adalah untuk mengungkap sedalam mungkin praktik diskursif dalam sebuah praktik sosial. Tesis dasarnya adalah wacana tidak tunggal dan dikendalikan oleh subyek yang berbicara, tetapi lebih dari itu dirumuskan dan diucapkan dalam sebuah konteks tertentu. Foucault menggunakan kata "episteme" untuk menjelaskan bagaimana sebuah wacana bermakna dalam sebuah konteks sejarah tertentu. Satu realitas bisa saja diinterpretasikan secara beragam oleh subyek tertentu, tergantung konstruksi pemaknaan yang hadir dalam subyek tersebut. Konstruksi pemaknaan ini tidak pernah lepas dari wacana yang hadir dalam sebuah situasi sosial tertentu. Untuk itu, wacana itu sendiri megandaikan empat hal yaitu, ada subyek yang mengatakan, ada dunia yang direpresentasikan, kepada siapa wacana itu 
Jurnal Pemikiran Sosiologi Volume 6 No.1 2019

Merebut Paus di Laut Sawu:

Konflik Kepentingan Konservasi Paus antara Negara dan Masyarakat Lamalera, Nusa Tenggara Timur Agustinus Gergorius Raja Dasion

disampaikan, dan temporalitas atau konteks waktu (Haryatmoko, 2016: 5).

Foucault memfokuskan hubungan pengetahuan, kekuasaan dan kebenaran dalam wacana. Wacana dilihat sebagai bahasa dalam praksis sosial, atau bahasa menjadi peristiwa sosial. Jadi, wacana menyediakan bahasa untuk membuat pernyataan (cara untuk merepresentasikan pengetahuan) tentang topik khusus pada periode sejarah tertentu. Foucault tertarik pada wacana sebagai aturan-aturan dan praktik-praktik wacana yang menghasilkan masalah-masalah yang bermakna dan diatur sesuai dengan periode sejarah, artinya ada struktur pemaknaan yang menentukan pada suatu periode sejarah tertentu (Ettlinger, 2011: 542).

Wacana tidak dapat berdiri sendiri. Wacana hadir dalam tindakan atau praktik sosial. Dalam cara pandang filsuf poststrukturalis ini, wacana tidak dapat berkembang di luar institusi, aparatus dan aktifitas. Dengan demikian wacana bahkan menjadi struktur berpikir dan bertindak dalam sebuah kehidupan publik. Wacana dipraktekkan dalam rutinitas tindakan dan normalisasi kesadaran masyarakat.Wacana merupakan sistem pengetahuan yang memberi informasi tentang teknologi sosial dan teknologi memerintah yang merupakan bentuk kekuasaan dalam masyarakat modern (Ettlinger, 2011: 538).

Ernesto Lacclau dan Chantal Mouffe mengikuti Foucault dalam menjelaskan wacana. Wacana adalah selalu bermakna karena berlaku dalam sebuah konteks tertentu. Laclau dan Mouffe menjelaskan bagaimana sebuah fenomena alam, misalnya gempa bumi atau runtuhnya sebuah jembatan, dikonstruksikan secara berbeda oleh subyek. Mungkin ada yang akan menanggapi fenomena tersebut sebagai gejala alam, namun yang lain akan mengartikan fenomena yang sama sebagai ekspresi dari murka atau kemarahan Allah (LaclauMouffe, 1985: 108).

Laclau menjelaskan secara baik bahwa wacana "diskursif" di sini bukan dimaksudkan untuk merujuk pada teks yang didefinisikan secara sempit, tetapi pada satu-kesatuan fenomena dimana produksi sosial atas makna berbeda, sebuah kesatuan yang membentuk masyarakat sebagaimana adanya. Karena itu, diskursif tidak dapat dianggap sebagai sebuah tingkatan sosial, bukan juga sebagai sebuah dimensi sosial, tetapi sama kuatnya dengan yang sosial. Ini artinya diskursif tidak membentuk superstruktur atau lebih tepatnya, seluruh praktik sosial membentuk dirinya sebagaimana sejauh ia memproduksi makna" (Smith: 1999: 8)

Wacana tidak hanya sebuah struktur gramatikal namun lebih dari itu wacana "memiliki daya magis" untuk bertindak dalam sebuah kehidupan sosial. Di sinililah sebenarnya konsep governmentalitas Foucault dapat dimengerti. Wacana bisa beroperasi melalui negara, dan lembaga-lembaga lainnya untuk membentuk sebuah kesadaran umum. Konsep governmentalitas bagi Foucault adalah sebuah taktik pemerintah (atau lembaga manapun) untuk secara terus menerus mendefinisikan atau meredefinisi segala yang harus diurus oleh negara dan apa yang tidak diurus oleh 
Jurnal Pemikiran Sosiologi Volume 6 No.1 2019

Merebut Paus di Laut Sawu:

Konflik Kepentingan Konservasi Paus antara Negara dan Masyarakat Lamalera, Nusa Tenggara Timur Agustinus Gergorius Raja Dasion

negara, yang publik dan yang privat, dan seterusnya" (Haryatmoko, 2016: 66).

Kerangka kedua adalah teori gevernmentaslitas. Konsep governmentalitas dapat dimengerti secara baik ketika memahami konsep kekuasaan Foucault. Baginya, kekuasaan tidak dapat dimiliki. Kekuasaan bukan sebuah mekanisme dominasi antara yang lebih kuat dengan yang lebih lemah. Kekuasaan itu adalah sebuah relasi kekuasaan dalam sebuah ruang sosial. Kekuasaan bukanlah sebuah distingsi oposisi biner karena kekuasaan hadir dalam pihak-pihak yang berelasi. Foucault bahkan menegaskan bahwa kekuasaan itu sendiri dapat memunculkan sikap anti kekuasaan (resistance) namun demikian ,konsep resistance tersebut tidak pernah hadir di luar wacana kekuasaan yang ada. Kekuasaan tidak lagi dilihat dalam sebuah paradigma sempit dalam sebuah hirarki "top-down" tetapi lebih dari itu, kekuasan harus dibaca dalam konteks kontrol sosial (social control) institusi serta pengetahuan. Bagi Foucault, kekuasaan itu merupakan ekspresikan dan hadir dalam praktek yang efektif (Ettlinger, 2011: 537). Bagi Foucault, konsep governmentalitas harus dimengerti melalui konsep teknik kekuasaan di mana hadir sistem dan manajemen kekuasan itu sendiri. Hal ini berarti kekuasaan itu bukan hadir sebagai daya dominasi tetapi lebih pada teknikteknik yang dilakukan agar kekuasan tetap ada dan tetap menjaga status quonya. Selain itu, konsep governmentalitas merujuk pada dua terminologi dasar yakni govern dan mentality, yang berarti menguasai mentalitas sosial atau governance of mentality (Ettlinger, 2011: 538).
Konsep governmentalitas merujuk pada dua teknologi kuasa yakni mengatur atau mendisiplinkan masyarakat atau to govern population dan mengatur diri atau to govern the self (Ettlinger, 2011: 540). Penelitian ini lebih memilih fokus pada konsep Foucalut "to govern the population", yakni bagaimana kuasa dilakukan untuk menguasai dan mendisiplinkan komunitas atau masyarakat. Walaupun demikian, terminologi to govern the self tidak bisa dilepaskan begitu saja sebab relasi keduanya adalah tetap saling berhubungan karena konsep governmentalitas selalu merujuk pada subyek yang di-govern (diatur atau diperintah).

Konsep ketiga adalah teori hegemoni Laclau dan Mouffe. Konsep hegemoni bukan asli milik Laclau dan Mouffe. Jauh sebelunya, konsep ini telah berkembang dalam arus pemikiran Marxisme. Hegemoni itu sendiri berkembang di Russia yakni ketika adanya konflik kelas menghadapi kekuasaaan monarki Russia. Namun demikian dalam perkembangannya, konsep ini semakin dikritisi dan semakin mendapatkan arti yang lebih "netral" yakni bahwa konsep hegemoni tidak hanya terfokus pada diskursus pertentangan kelas (Laclau -Mouffe, 2001:9)

Konsep ini semakin berkembang dimulai dari pemikiran Antonio Gramsci. Gramsci sendiri menjelaskan hegemoni sebagai praktik dua arah dari dua hubungan yang bersifat subordinasi, yakni kekuasaan negara borjuis dan kelas buruh (Jorgensen and Phillips, 2004 : 25). Laclau dan Mouffe sendiri tidak menolak konsep hegemoni Gramsci yang dipandang sebagai sebuah formasi 
Jurnal Pemikiran Sosiologi Volume 6 No.1 2019

Merebut Paus di Laut Sawu:

Konflik Kepentingan Konservasi Paus antara Negara dan Masyarakat Lamalera, Nusa Tenggara Timur Agustinus Gergorius Raja Dasion

hegemoni yang baru. Bagi Laclau dan Mouffe, Gramsci telah keluar dari deterministik identitas kelas peninggalan Plekhanov dan Lenin, dan memfokuskan pada pengelompokan sosial yang lebih luas yang ia sebut "blok historis" di mana kesatuan tujuan atau "keinginan kolektif" yang diusung atas dasar kepemimpinan intelektual dan moral dalam konteks hegemoni politik dan kulturl (Hutagalung, 2008: 12).

Bagi Gramsci, hegemoni itu lahir ketika kelas yang berkuasa berhasil memperkuat posisi mereka dengan menyingkirkan kekuatan oposisi dan memenangkan persetujuan (consensus). Gramsci menambahkan bahwa "proyek" hegemonik pun bisa hadir dari masyarakat ketika mereka membangun kekuatan politiknya untuk menghadapi rezim yang ada di atasnya (Laclau and Mouffe, 2001: 27). Laclau dan Mouffe hadir dalam pandangan yang sama. Keduanya mengkritisi Gramsci sekaligus memberi "pencerahan" bagi teori hegemoninya. Laclau dan Mouffe tidak lagi memfokuskan praktek hegemoni pada kelas buruh yang merasa "tertindas" oleh kelompok yang ada di atasnya. Keduanya mengeser paradigma Gramsci tentang analisa kelas menuju analisa discourse (discourse analysis). Analisa wacana memungkinkan kekuasaan dalam sebuah wacana dapat dibaca (Dabirimehr and Fatmi, 2014 : 1243). Untuk itu, titik tolak Laclau dan Mouffe adalah bagaimana berusaha untuk mengidentifikasi struktur struktur kekuasaan wacana yang pada akhirnya membentuk aksi kolektif sebagai usaha melawan ketidakadilan dan relasi yang subordinat (Laclau and Mouffe, 2001: 93).
Konsep hegemoni Laclau dan Mouffe secara umum memiliki validitas dalam menganalisa proses disartikulasi dan reartikulasi yang bertujuan menciptakan dan menjaga politik sebagaimana juga kepemimpinan moral-intelektual. Bagi keduanya, hegemoni merupakan praktik artikulasi yang membangun nodal points (titik temu dalam sebuah rangkaian) yang secara parsial memperbaiki makna dari yang sosial dalam sebuah sistem difference yang terorganisasi (Laclau-Mouffe dalam 2001: 93). Kosep hegemoni dapat dimengerti secara lebih lengkap ketika menelusuri konsep antagonisme. Laclau dan Mouffe melihat bahwa hegemoni akan muncul dalam situasi antagonisme, misalnya rezim yang menindas rakyat, yang memungkinkan terbentuknya "political frontier". "Political frontier" akan menciptakan pertarungan hegemonik, di mana dalam situasi ini akan terbangun apa yang disebut dengan rantai kesetaraan atau "chain of equivalen" di atara kelompok sosial yang melakukan resistensi tehadap rezim penindas (Laclau-Mouffe 2001: 93198).

Laclau dan Mouffe menjelaskan bahwa salah satu karakteristik hegemoni yang membedakan pemikiran hegemoni milik mereka dengan yang lain adalah adanya desakan dari dalam subyek. Subyek menjadi hal yang cukup dipandang krusial dalam mendiskusikan hegemoni Laclau dan Mouffe sebab justru subyek inilah yang akan menghasilkan partikular-partikular menuju sebuah kesetaraan/ equivalences (Walton and Boon, 2014: 353).

Gerakan menuju hegemoni sebenarnya terarah dan terstruktur. Seperti ia contohkan perjuangan menuju collective will (keinginan 
Jurnal Pemikiran Sosiologi Volume 6 No.1 2019

Merebut Paus di Laut Sawu:

Konflik Kepentingan Konservasi Paus antara Negara dan Masyarakat Lamalera, Nusa Tenggara Timur Agustinus Gergorius Raja Dasion

bersama) Rosa Luxemburg. Hegemoni dimulai dengan gerakan partikular untuk menolak rezim penindas (anti-system). Partikularitas dan antisistem akhirnya saling besatu dalam sebuah kesetaraan (chain of equivalence). Munculnya sebuah batas (frontier) yang memisahkan rezim penindas dengan masyarakat adalah kondisi paling baik bagi universalisasi tuntutan melalui bermacammacam kesetaraan atau equivalences (LaclauMouffe, 2001: XVIII).

\section{Negara Membangun Wacana Konservasi Laut} Sawu

Sebelum tahun 2000, tradisi perburuan paus Lamalera dianggap sebagai salah satu budaya yang unik dan harus dilestarikan. Negara, lewat Dinas Pariwisata dan Ekonomi Kreatif Provinsi NTT memperkenalkan wisata berburu paus secara tradisional (tradisional whaling) dalam berbagai program unggulannya. Namun dukungan terhadap pelestarian tradisi berburu paus Lamalera akhirnya berubah. Negara kini mulai membangun wacana baru terkait tradisi melaut masyarakat Lamalera. Salah seorang tokoh adat Lamalera, NSB (70), yang juga merupakan salah seorang pembuat perahu/ tena (ata mole), menuturkan bahwa pada awalnya masyarakat tidak pernah berpikir tentang nasib tradisi ini akan terganggu oleh isu konservasi yang datang dari luar. Ia menjelaskan bahwa masyarakat Lamalera hanya ingin hidup apa adanya dan mengharapkan orang atau kelompok lain tidak masuk dan mencampuri kehidupan dan budaya mereka. Ia mempertanyakan niat dan tujuan pemerintah dalam melaksanakan program konservasi paus di Laut Sawu yang sebenarnya masyarakat lokal pun memiliki aturan aturan adat dalam menjaga kelestarian ekosistem laut.

Tujuan konservasi yang sedang diperjuangkan oleh negara dan lembaga-lembaga konservasi laut adalah untuk menjaga keseimbangan ekosistem. WWF (World Wild Fund) dan TNC (The Nature Conservancy) sendiri merupakan lembaga yang bergerak dalam upaya konservasi laut. WWF Indonesia berusaha melakukan berbagai penelitian dan menemukan ancaman bagi ekosistem di laut dan bagi mereka, ancaman terbesar terhadap keseimbangan ekosistem laut adalah berasal dari manusia. Tujuan program konservasi WWF Indonesia tertuang dalam Kerangka Kerja "KKP (Kawasan Konservasi Perairan) untuk perikanan berkelanjutan" dengan tiga tujuan jangka panjang, yaitu:

a. Menyediakan stok sumberdaya ikan yang sehat dan melimpah,

b. Melindungi habitat laut penting,

c. Mendorong kesejahteraan masyarakat.

Dengan demikin, berbagai program yang dilakukan lembaga ini bertujuan untuk menjaga keanekaragaman hayati di Indonesia khususnya dan dunia pada umumnya (http://awsassets.wwf.or.id, 2017).

Selain itu, TNC hadir dalam konsep yang kurang lebih sama dengan WWF. Dengan motto "melindungi alam, melestarikan kehidupan", TNC bermitra dengan pemerintah untuk bekerjasama mengelola sumeberdaya laut secara lestari melalui "Inisiatif Segitiga Terumbu Karang”. Strategi program kelautan Indonesia untuk mewujudkan 
Jurnal Pemikiran Sosiologi Volume 6 No.1 2019

Merebut Paus di Laut Sawu:

Konflik Kepentingan Konservasi Paus antara Negara dan Masyarakat Lamalera, Nusa Tenggara Timur

Agustinus Gergorius Raja Dasion

pengelolaan sumberdaya alam laut secara lestari adalah:
a. Perlindungan sumberdaya alam laut.
b. Pemanfaatan sumberdaya laut secara berkelanjutan.
c. Pengembangan tata ruang laut.
d. Pengembangan wilayah pesisir yang tangguh (https://www.nature.or.id).

Negara lewat aparaturnya berusaha membangun kesadaran masyarakat tentang wacana konservasi paus. Lewat berbagai seminar, sosialisasi, program, dan baliho, negara berusaha membangun wacana tersebut semakin besar dan semakin berkembang di ranah masyarakat lokal. Lewat wacana konservasi, negara berusaha membangun kesadaran masyarakat tentang keseimbangan alam dan peningkatan ekonomi lokal. Dinas Pariwisata dan ekonomi Kreatif Provinsi Nusa Tenggara Timur dan Dinas Pariwisata dan Kelautan Kabupaten Lembata menjadi dua instansi pemerintah yang sangat aktif dalam membangun kesadaran masyarakat akan wacana konservasi Laut Sawu. Selain itu, Dinas Kelautan Provinsi Nusa Tenggara Timur dan Balai Besar Konservasi Sumber Daya Alam Provinsi Nusa Tenggara Timur juga turut mensosialisasikan wacana yang sama.

Berbagai seminar dan sosialisasi telah dilakukan oleh negara lewat aparatusnya. Seminar dan sosialisasi tersebut berusaha untuk tetap pada tujuan utamanya yakni memberi pemahaman kepada masyarakat lokal dalam menjaga keseimbangan ekosistem laut. Dari berbagai kegiatan, seminar, dan sosialisasi tentang wacana konservasi paus di Laut Sawu, ada beberapa peristiwa yang patut dijadikan catatan.

Wacana konservasi mulai didengar oleh masyarakat Lamalera pada tanggal 14 Juli 2007. Bertempat di pusat kampung Lamalera A, yakni di depan rumah adat suku Levotukan, dilaksankan seminar budaya terkait wacana konservasi paus. Seminar tersebut digagas oleh Dinas Pariwisata dan Kelautan Kabupaten Lembata dan Lembaga Yayasan Bina Sejatera (YBS). Seminar yang sedang berlangsung, akhirnya dibubarkan secara paksa oleh masyarakat Lamalera yang merasa bahwa seminar ini membawa agenda tersembunyi dari pemerintah dan beberapa lembaga terkait wacana konservasi paus. BB, salah seorang aktivis Lamalera, menuturkan bahwa seminar yang dimaksud bertujuan untuk mengajak masyarakat Lamalera untuk mulai menerima program pariwisata menonton paus (whale watching) di Lamalera.

Wacana konservasi paus akhirnya benarbenar terealisasi dengan dibentuknya Kawasan Konservasi Laut Daerah Solor-Lembata-Alor (KKLDSolar). KKLD-Solar akhirnya ditetapkan secara resmi oleh SK Gubernur NTT di tahun 2006. KKLD Solar diinisiasi oleh WWF (World Wild Fund) dan TNC (The Nature Conservancy) dalam rangka mensukseskan program kedua lembaga tersebut dalam menjaga keanekaragaman hayati laut.

Pada tahun 2010, CTI (Coral Triangel Initiative) dan DKP-RI mengeluarkan aturan Kawasan Konservasi Perairan Nasional (KKPN) di Laut Sawu dengan tiga zona konservasi. Aturan ini disahkan melalui Kepmen Kelautan dan Perikanan RI No. 38/KEPMEN/2009 tentang Pencadangan 
Jurnal Pemikiran Sosiologi Volume 6 No.1 2019

Merebut Paus di Laut Sawu:

Konflik Kepentingan Konservasi Paus antara Negara dan Masyarakat Lamalera, Nusa Tenggara Timur Agustinus Gergorius Raja Dasion

Kawasan Konservasi perairan Nasional Laut Sawu dan Sekitarnya di Provinsi Nusa Tenggara Timur. Zona kedua yang menjadi kawasan yan dikonservasi adalah lokasi di mana masyarakat Lamalera memburu dan menangkap paus. Dengan berbagai aksi penolakan masyarakat Lamalera, akhirnya zona kedua Laut Sawu dikeluarkan dari zona konservasi nasional. Namun dikelurakannnya zona II konservasi Laut Sawu tidak membawa rasa aman bagi masyarakat Lamalera. Masyarakat tetap hidup dalam kecemasan dan saling menyalahkan dengan berbagai sosialisasi yang dilakukan pemerintah hingga sekarang. Kawasan Konservasi Laut Sawu akhirnya dipertegas kembali dengan Kepmen Kelautan dan Perikanan RI No.5/KEPMEN-KP/2014.

Pada tanggal 14 Desember 2014, bertempat di Lewoleba, diselenggarakan seminar ikan paus oleh Dinas Pariwisata dan Kelautan Kabupaten Lembata dan Dinas Pariwisata dan Ekonomi Kreatif Provinsi NTT. Pada kesempatan ini pemerintah mulai mewacanakan konsep wisata "berburu paus menggantikan menonton paus" (whale hunting to whale watching). Beberapa perwakilan masyarakat Lamalera yang diundang langsung mengajukan keberatan tentang konsep yang ditawarkan. Mereka mengklaim bahwa penangkapan ikan paus yang selama ini dilakukan masih menggunakan alat tradisional dan hanya untuk mempertahankan hidup (Kompas.com 24/12/2014).

Pada tangal 31 Oktober 2016, bertempat di pusat desa Lamalera (namang) diadakan sosialisasi tentang wisata bahari. Sosialisasi ini dilakukan oleh Dinas Pariwisata dan Ekonomi Kreatif NTT dan dihadiri juga oleh wakil dari Kementerian
Koordinator bidang Kemaritiman. Dalam sosialisasi ini, menurut tokoh adat Lamalera JB, dijelaskan bahwa budaya berburu paus yang dilakukan oleh masyarakat Lamalera tetap dihormati. Namun demikian, diharapkan adanya koordinasi yang baik dari masyarakat lokal dan pemerintah agar ekosistem paus tidak punah. Sehari sebelumnya, telah dilakukan seminar di Lewoleba ibu kota kabupaten Lembata, dengan tema "Penguatan Budaya Maritim-Budaya Lefa Dalam Rangka Pengembangan Destinasi Wisata Bahari dan Pengelolaan Sumber Daya" (Pos Kupang.com 5 November 2016).

Pada tanggal 15 Juni 2017, diadakan seminar yang diselenggarakan oleh Dinas Pariwisata dan Ekonomi Kreatif Provinsi NTT dalam kerjasama dengan TNC (The Nature Conservacy). Seminar dilakukan dengan menggusung tema "Rencana Bisnis Wisata Menonton Paus di Provinsi Nusa Tenggara Timur". Seminar tersebut merupakan program lanjutan dari dinas terkait tentang rencana wisata menonton paus yang telah ditargetkan mulai tahun 2018. Pasca seminar tersebut, program unggulan pariwisata NTT diarahkan pada pariwisata di Laut Sawu (Media NTT.com 15 Juni 2017).

Sejak tahun 2007 hingga sekarang, Dinas Pariwisata dan Ekonomi Kreatif Provinsi NTT telah bekerjasama dengan beberapa lembaga besar seperti yakni WWF Indonesia (World Wild Fund) dan TNC (The Natural Conservancy) dalam mensosialisasikan seluruh program konservasi Laut Sawu. WWF (World Wild Fund) sebenarnya memiliki pengalaman yang kurang baik terhadap 
Jurnal Pemikiran Sosiologi Volume 6 No.1 2019

Merebut Paus di Laut Sawu:

Konflik Kepentingan Konservasi Paus antara Negara dan Masyarakat Lamalera, Nusa Tenggara Timur Agustinus Gergorius Raja Dasion

masyarakat Lamalera. Menurut AGT, salah seorang penikam paus (lamafa), WWF masuk ke desa Lamalera tahun 2006. Di tahun tersebut, WWF memperkenalkan masyarakat tentang konservasi laut. Tidak hanya itu, WWF bahkan sempat bekerjasama dengan National Geographic Indonesia dan melaksanakan program photovoice. Photovoice adalah program di mana masyarakat dibagi kamera dan diminta untuk memotret seluruh aktivitas mereka untuk didokumentasikan dan dipublikasikan kepada pihak lain.

Di lingkup pemerintahan Kabupaten Lembata sendiri, WWF menjadi parter dalam mensosialisasikan seluruh program pemerintah tentang konservasi laut di Lembata. Komitmen untuk menjaga kelestarian alam tersebut diresmikan dengan menandatangani kesepakatan pembetukan kawasan konservasi perlindungan laut Solor-Lembata-Alor di Lewoleba, Lembata pada tanggal 30 April 2007. Komitmen ini berhasil ditandatangani oleh Bupati Kab. Flores Timur, Kab. Lembata, Kab. Alor, Gubernur NTT, Tim PP-KKL, Program Kelautan TNC dan WWF Indonesia. (Desrianti, 2011: 113).

Selain WWF, lembaga lain yang pernah ke Lamalera adalah Whale Dolpin Watching Program (WDWP). Lembaga ini menjadi lembaga pertama yang mengusung misi whale watcing menggantikan whale hunting yang selama ini dijalankan masyarakat Lamalera. Menurut AGT, sang juru tikam (lamafa), masyarakat langsung menolak program yang ditawarkan WDWP sekaligus mengancam para pegiat WDWP untuk tidak lagi kembal ke Lamalera.
Sejak kedatangan Lembaga WDWP ke Lamalera, masyarakat mulai merasa terusik dengan kehadiran lembaga-lembaga asing tersebut. Awalnya masyarakat merasa senang dengan bergitu banyak orang asing yang masuk di Lamalera. Ada kesan bahwa budaya Lamalera adalah budaya yang unik sehingga menarik minat begitu banyak orang untuk datang ke Lamalera. Namun ketika lembagalembaga tersebut mengusik cara hidup dan tradisi mereka dalam hubungan mereka dengan laut maka mereka secara langsung menolaknya.

\section{Lamalera dan Wacana Konservasi Paus Lokal}

Tradisi berburu paus masyarakat Lamalera telah dilakukan jauh sebelum kedatangan pemburu paus dari Amerika dan Inggris di perairan timur Indonesia (Barnes 1996: 323). Dengan demikian, munculnya wacana konservasi Laut Sawu dengan pembentukan Kawasan Konservasi Laut Daerah Solor-Lembata-Alor (KKLD-Solar) di tahun 2006 menjadi masalah serius bagi masyarakat Lamalera. Tidak hanya itu, berbagai program dari Dinas Pariwisata di tingkat provinsi dan kabupaten yang begitu masif dilakukan menjadi hal yang sangat mengganggu kehidupan masyarakat lokal.

Di lingkup masyarakat Lamalera, konservasi alam bukanlah hal yang baru. Konservasi yang dilakukan secara lokal dapat dimengerti sebagai upaya pemeliharaan alam yang terukur dan berkesinambungan. Masyarakat memiliki cara sendiri dalam memanfaatkan sumber daya alam dengan tetap mematuhi berbagai aturan adat dan larangan. Konsep konservasi lokal bisa disebut sebagai kearifan lokal masyarakat dalam menjaga 
Jurnal Pemikiran Sosiologi Volume 6 No.1 2019

Merebut Paus di Laut Sawu:

Konflik Kepentingan Konservasi Paus antara Negara dan Masyarakat Lamalera, Nusa Tenggara Timur Agustinus Gergorius Raja Dasion

seluruh sumber daya alam yang menopang kehidupan mereka (Kopnina, 2012: 131). Konsep konservasi lokal hadir dalam berbagai cara hidup, etika, filsafat dan spiritual dari masyarakat Lamalera, termasuk dalam melaksanakan tradisi penangkapan paus. Konsep konservasi lokal inilah yang menjadi rujukan yang kuat dalam menjawab wacana konservasi global yang ditawarkan negara.

Pertama, secara filosofis, bagi masyarakat Lamalera, paus adalah binatang yang suci. Menurut BK, antropolog Universitas Nusa Cendana, yang juga adalah putera asli Lamalera, paus tidak hanya hadir sebagai makanan demi kebutuhan hidup masyarakat Lamalera, tetapi lebih dari itu merupakan pengejawantahan leluhur dan berkah dari yang empunya hidup (Alepte). Dengan demikian, kegiatan mengangkap paus bernilai spiritual dan teologis. Hal ini muncul lewat syair yang biasanya dinyanyikan ketika hendak menancapkan tombak (leke/ tempuling) pada tubuh paus. "Sora tare bala, ..tala lefo rae tai" (kerbau bertanduk gading, marilah ke kampung). Paus bagi orang Lamalera adalah ibarat kerbau bertanduk gading. Kerbau sendiri dianggap hewan yang sangat prestisius dalam adat dan budaya masyarakat Lamalera. Biasanya kerbau (sora) dikorbankan pada acara-acara adat yang besar. Selain itu, gading (bala) juga merupakan benda yang sangat berharga. Dalam adat perkawinan masyarakat Lembata, gading menjadi syarat utama (belis) jika ingin mempersunting seorang gadis.

Kedua, menurut NSB, pembuat perahu (ata mole), penangkapan paus merupakan satu kesatuan dari seluruh siklus hidup masyarakat Lamalera.
Siklus hidup masyarakat Lamalera ditandai dengan berbagai ritus termasuk ritus sebelum ke laut hingga saat menikam paus. Ritus-ritus itu antara lain adalah ritus ile gerêk (upacara memanggil paus di batu ikan paus), ritus tobu nama fattê (urung rembuk di pantai), misa arwah (ibadat atau/ missa kudus untuk keselamatan arwah leluhur yang mati di laut), misa leffâ (missa kudus di bibir pantai Lamalera setiap awal musim melaut untuk menyucikan laut, nelayan, juru tikam, perahu dan layar), dan tenna fulê (upacara memasuki laut pada awal pembukaan musim melaut oleh perahu perdana). Semua ritus ini dilaksanakan secara beruntun dan berkesinambungan serta menyatu-padu (integrated) sehingga tidak dapat dipisahkan antara satu dengan yang lain. Melalui pelaksanaan berbagai ritus, masyarakat setempat percaya bahwa ritusritus tersebut mampu memberikan berkat melimpah selama setahun. Berkat ditandai dengan hasil tangkapan paus yang cukup dan kehidupan masyarakat yang tenteram tanpa ada pertikaian antar suku. Ritus ini pun menjadi tanda kesatuan masyarakat Lamalera dengan para leluhur mereka. Hal ini terlihat dalam syair adat berikut, 'Inate amate gena ola, ola kae toe tai/ tite bai mi ola plau lefa pe bata na mura/ ara puka ina-amate gena kae/ tite tode tairo' (Nenek-moyang sudah mewariskan kerja ini, karena merupakan kerja, maka haruslah kita jalankan/ kita merasakan bahwa pekerjaan di laut itu sungguh berat/ tetapi karena nenek-moyang kita sudah mewariskan/ kita harus tetap menjalankannya). Syair ini juga membuktikan bagaimana masyarakat Lamalera patuh pada tradisi yang telah hadir secara turun temurun. 
Jurnal Pemikiran Sosiologi Volume 6 No.1 2019

Merebut Paus di Laut Sawu:

Konflik Kepentingan Konservasi Paus antara Negara dan Masyarakat Lamalera, Nusa Tenggara Timur Agustinus Gergorius Raja Dasion

Ketiga, masyarakat menilai bahwa dengan cara penangkapan paus secara tradisional dan mengikuti berbagai aturan adat, keseimbangan ekosistem tetap terjaga. Masyarakat Lamalera sendiri memburu paus menggunakan alat tradisional. Perahu (tena) yang digunakan oleh masyarakat Lamalera merupakan perahu tradisional yang tidak pernah berubah bentuknya dari dahulu hingga sekarang. Dengan perahu (tena) tersebut, para nelayan akan pergi ke laut dan mencari paus. Ketika menemukannya, seorang juru tikam (lamafa) akan berdiri di depan perahu (tena) dan melompat sambil menancapkan sebilah lembing atau semacam tombak (leke/tempuling) pada tubuh paus. Jika berhasil maka semua anggota perahu (meing/matros) akan berusaha menarik paus tersebut hingga bisa mendapatkannya. Tradisi masyarakat Lamalera ini sebenarnya telah dilindungi oleh moratorium lembaga internasional paus yakni IWC (International Whaling Commision) sebab menangkap paus yang di lakukan adalah dalam kerangka ekonomi subsisten. Subsistensi masyarakat Lamalera dapat dilihat dari cara penangkapan paus dan cara pengolahan dan pemanfaatannya (Nolin, 2010 : 249).

Selain alat penangkapan yang masih tergolong tradisional, penentuan musim melaut menjadi hal unik dalam menjaga keseimbangan alam secara lokal. Musim melaut masyarakat Lamalera hanya dilakukan selama enam bulan dalam setahun (lefa nuang). Setiap tahun masyarakat Lamalera biasanya berburu paus dari bulan April hingga Oktober. Pada bulan-bulan selain musim melaut (lefa nuang), masyarakat akan mencari ikan-ikan kecil lainnya untuk memenuhi kebutuhan hidup mereka. Kepatuhan akan waktu berburu paus sangat ditaati dan tidak pernah dilanggar.

Daging paus yang sudah didapat biasanya langsung dipotong dan dibagikan ke seluruh masyarakat sesuai dengan aturan adat yang telah ditentukan. Pada umumnya, daging paus yang didapat dipergunakan untuk memenuhi kebutuhan sehari-hari (Alvard, 2011 : 93). Bagi masyarakat Lamalera, selain untuk konsumsi sehari-hari, daging paus tersebut akan dijadikan bahan barter setiap hari Sabtu untuk bisa mendapatkan beras, jagung, ubi, dan pisang dari daerah pegunungan. Pasar barter ini diadakan setiap minggu di Lamaera dengan menghadirkan para penjual hasil pertanian dari gunung Labalekan (Barnes, 2016: 399-407).

Batas wilayah atau teritori masyarakat Lamalera sudah ditentukan secara adat. AGT sebagai juru tikam paus (lamafa) menjelaskan secara baik batas-batas wilayah dan aturan yang harus dipatuhi para nelayan Lamalera. Masyarakat Lamalera sangat percaya bahwa ketika melanggar batas wilayah yang dimaksud berarti bersedia menerima resiko atau bahaya yang bisa saja terjadi. Batas-batas melaut masyarakat Lamalera adalah :

a) Di bagian timur berbatasan dengan Tanjung Atadei.

b) Di bagian barat berbatasan dengan Pulau Suanggi (pulau kecil tanpa penghuni yang terletak di dekat Tanjung Naga).

c) Jarak antara bibir pantai ke laut dalam disebut dengan pnutu buka. Pnutu buka adalah ketika jarak pandang terhadap Gunung Labalekang dan Gunung Mingar 
Jurnal Pemikiran Sosiologi Volume 6 No.1 2019

Merebut Paus di Laut Sawu:

Konflik Kepentingan Konservasi Paus antara Negara dan Masyarakat Lamalera, Nusa Tenggara Timur

Agustinus Gergorius Raja Dasion

sejajar dengan permukaan laut atau dalam bahasa adat (lefo gerefa kae ne ile minger gene ile Labalekan).

Selain itu AGT, sang juru tikam (lamafa) juga menjelaskan beberapa aturan adat lain yang harus dipatuhi. Aturan-aturan tersebut adalah:

a) Tidak boleh meneruskan pengejaran terhadap paus jika tiba-tiba menemukan seperti daratan di tengah laut (hari leva) nong ne kaju lolong).

b) Paus biru (balaenoptera musculus) atau dalam bahasa Lamalera disebut klaru, tidak boleh ditikam sebab dipercaya sebagai paus yang telah membantu masyarakat Lamalera ketika eksodus pertama ke Lamalera.

c) Paus yang sedang hamil tidak boleh ditikam. Para juru tikam (lamafa) mampu mengidentifikasi paus yang sedang hamil. Selain itu juga, pengetahuan lokal tentang paus yang masih kecil dan sudah dewasa menjadi standar dalam menikam paus.

d) Jika menemukan sekumpulan paus yang beranggotakan paus jantan, betina dan anakanak maka yang boleh ditikam hanya paus jantan. Paus betina harus dibiarkan untuk menjaga anak-anaknya hingga besar.

e) Dalam melaut, para nelayan selalu melihat arah angin dan letak matahari. Jika matahari sudah hampir terbenam, ikan yang sedang dikejar harus direlakan pergi. Ketika merelakan ikan pergi, semua nelayan harus berseru bahwa "te baongte ki, mo maiko tapi beu pe mo baliko bali" (hari ini engkau pergi tetapi semoga besok engkau harus kembali).

f) Posisi ikan paus dengan peledang (perahu) juga menetukan apakah ikan tersebut dapat ditikam atau tidak. Posisi ikan yang lurus (entah membelakangi atau berhadapan) dengan perahu maka penikam (lamafa) harus mengurungkan niat untuk menikam paus tersebut.

g) Paus harus dihormati sebab ikan tersebut yang memberi kehidupan bagi masyarakat Lamalera. Hal ini tertuang dalam syrair adat berikut, "raja dai geri lefo, maje ribu ratu gole ile lodo lili raja pau lefo" (Raja datang untuk memberi makan kampung, panggil seluruh masyarakat di gunung untuk turun mengikuti acara tersebut).

h) Masyarakat Lamalera percaya akan hubungan kehidupan di laut dan di darat.

Dengan demikian, apa saja yang terjadi di laut merupakan cerminan segala yang terjadi di darat. Hal ini berarti keharmonisan hidup masyarakat di darat akan terlihat dari banyaknya tangkapan dan keberhasilan dalam melaut. Syair adat Lamalera berbunyi "kajo te tojo ike gepa tanah, tanah gepa tena, tena gepa tai, tai gepa ike (koteklema), ike gepa atadike" (tiang penggantung ikan akan memberitahu tanah, tanah akan memberitahu perahu, perahu akan memberitahu laut, dan pada akhirnya laut akan memberitahu ikan dan ikan akan memberitahu kepada nelayan yang melaut).

Jika ada yang melanggar salah satu aturan di atas, maka akan terjadi situasi di mana paus sulit ditangkap dan hal ini bisa terjadi beberapa bulan 
Jurnal Pemikiran Sosiologi Volume 6 No.1 2019

Merebut Paus di Laut Sawu:

Konflik Kepentingan Konservasi Paus antara Negara dan Masyarakat Lamalera, Nusa Tenggara Timur Agustinus Gergorius Raja Dasion

bahkan tahun (ike kbuenga). Situasi seperti ini harus diselesaikan dengan melakukan ritual adat dan rekonsiliasi. Ritual yang benar dan rekonsliliasi yang tulus akan berakibat baik bagi kembalinya tangkapan yang berlimpah.

\section{E. Kesimpulan}

Wacana tidak pernah tunggal. Hal ini berarti di dalam sebuah wacana, hadir kekuasaan dan subyek yang mengkonstruksi wacana tersebut. Foucault menjelaskan bahwa wacana tidak pernah bebas nilai sebab wacana adalah ruang di mana kekuasaan saling berkontestasi antara satu dengan yang lainnya. Wacana konservasi Laut Sawu yang sedang digiatkan oleh negara lewat Dinas Pariwisata dan Ekonomi Kreatif provinsi NTT juga tidak pernah bebas dari segala praktik kekuasaan. Negara memiliki kuasa dalam membangun narasi besar tentang konservasi paus di laut sawu. Narasi tersebut terkait wacana konservasi demi menjaga keseimbangan dan keberlangsungan habitat di laut. Tidak hanya itu, wacana eco-tourism menjadi wacana baru yang cukup kuat digaungkan negara dan para pencinta lingkungan (Graca: 2002: 126).

Ketika negara membangun wacana konservasi Laut Sawu, masyarakat Lamalera yang selama hidupnya berhubungan dengan laut juga memiliki kuasa dalam membangun wacana mereka sendiri. Wacana konservasi lokal dibangun masyarakat Lamalera untuk "menjawab" wacana konservasi yang digagas oleh negara. Masyarakat yang setiap hari mencari paus demi memenuhi kebutuhan hidup (subsisten) memiliki cara sendiri dalam menjaga ekosistem laut sehingga tetap berkesinambungan. Masyarakat lokal Lamalera memiliki ethos hidup lokal dalam memanfaatkan sumber daya alam dengan tetap mematuhi berbagai aturan adat dan larangan. Konsep ini bisa disebut sebagai kearifan lokal masyarakat dalam menjaga seluruh sumber daya alam yang menopang kehidupan mereka (Kopnina, 2012: 131).

Wacana konservasi Laut Sawu yang diprogramkan negara dan juga beberapa lembaga konservasi alam tidak boleh dibaca hanya sebagai upaya untuk menyelamatkan Laut Sawu dari kepunahan ekosistem di dalamnya. Wacana konservasi yang sudah dibarengi dengan wacana pariwisata bisa mengaburkan tujuan utama konservasi itu sendiri. Untuk itu, dibutuhkan sebuah kajian yang lebih mendalam bagaimana masyarakat Lamalera dalam menjaga keseimbangan ekosistem di Laut Sawu.

Selain itu, pemerintah seharusnya memberikan ruang bagi masyarakat Lokal dalam membangun wacana konservasi lokal yang lebih pasti dan tepat. Beberapa aturan lokal telah menjadi bukti konkrit bagaimana masyarakat lokal memiliki andil besar dalam menjaga kelestarian alam. Upaya ini dapat menjadi ruang diskusi yang lebih adil antara wacana konservasi laut yang digagas negara dan konsep konservasi lokal yang dipertahankan masyarakat Lamalera.

\section{Daftar Pustaka}


Jurnal Pemikiran Sosiologi Volume 6 No.1 2019

Merebut Paus di Laut Sawu:

Konflik Kepentingan Konservasi Paus antara Negara dan Masyarakat Lamalera, Nusa Tenggara Timur

Agustinus Gergorius Raja Dasion

Alvar, Michael. 2001. "Genetic and Cultural Kinship among the Lamaleran Whale Hunters." Springer Science Business Media. Vol. 12. (2): 98-107.

2003. "Kinship, Lineage, and An Evolutionary Perspective on Cooperative Hunting Grups In Indonesia." Human Nature. Vol. 14 (2) 2:129-163.

Barnes, Robert H. 1996. Sea Hunters of Indonesia: Fishers and Weavers of Lamalera. Oxford: Clarendon Press.

Barnes, Robert H. and Ruth Barnes. 1989. "Barter and Money in an Indonesian Village Economy." Royal Anthropological Institute of Great Britain and Ireland Vol. 24 (3): 339418.

Benton, Ted and Ian Craib. 2001. Philosophy of Social Science. New York: Palgrave.

Blikololong, Yakobus. 2010. "Du-Hope di Tengah Penetrasi Ekonomi Uang." Disertasi. Jakarta: UI. Tidak Diterbitkan.

Dabirimehr, Amir and Fatmi, MT. 2014. "Laclau and Mouffe Theory of Discourse." JNAS Journal. Vol.3 (11): 1283-1287.

Destriani, Febriani. 2011. "Perubahan Sosial Masyarakat Lamalera." Tesis. Bogor: IPB. Tidak Diterbitkan.

Etlinger, Nanci. 2011. Governmentality as Epistemology. USA: Routledge: 530-560.

Fairclough, N. 2010. Critical Discourse Analysis: The Critical Study of Language. Longman: Edinburg.
Graca, Katja Neves. 2002. “A Whale of a Thing: Transformations from Whale Hunting to Whale”. Doktoral Thesis. New York. Graduate Programme in Social Anthropology, New York University.

Haryatmoko. 2016. Membongkar Rezim Kepastian : Pemikiran Kritis Post Strukturalis. Yogyakarta: Kanisius.

2016. Critical Discourse Analysis. Jakarta: Rajawali Press.

Hutagalung, D. 2004. "Hegemoni, Kekuasaan, dan Ideologi." Jurnal Pemikiran Sosial, Politik, dan Hak Asasi Manusia, No. 12, OktoberDesember: 1-17.

2008. Hegemoni dan Demokrasi Radikal-Plural: Membaca Laclau dan Mouffe. Yogyakarta: Resist Book.

Jorgensen, M and Louisse J. Phillips. 2002. Discourse Analysis as Theory and Method. California: Sage Publication, Ltd.

Kopnina, Helen. 2012. "Toward Conservational Anthropology: Addressing Anthropocentric bias in Anthropology." Dialec Antropol. Vol. 36: 127-146

Laclau, Ernesto dan C. Mouffe. 2001. Hegemony and Social Strategy. New York: Verso.

Laclau, Ernesto. 1994. The Making of Political Identities. New York: Verso.

Nolin, A. David 2010. "Food-Sharing Networks in Lamalera, Indonesia." Reciprocity, Kinship, and Distance, Springer Vol. 21: 243-268. 
Jurnal Pemikiran Sosiologi Volume 6 No.1 2019

Merebut Paus di Laut Sawu:

Konflik Kepentingan Konservasi Paus antara Negara dan Masyarakat Lamalera, Nusa Tenggara Timur

Agustinus Gergorius Raja Dasion

Nugroho, Heru. 1997. “Garda Terdepan Penjaja Komoditi Budaya". Jurnal Ilmu Sosial dan Ilmu Politik, UGM Vol. 1 (2): 63-72.

Smith, Ana Marie. 1998. Laclau -Mouffe: The Radical Democratic Imaginary. USA: Routledge.

Torfing, Jacob. 1999. The New Theories of Discourse: Laclau, Mouffe, and Zizeck. USA: Blackwelll Publisher.

Walton S dan Bronwyn Boon. 2014. "Engaging With a Laclau \& Mouffe Indformed Discourse Analysis. Qualitative Research in Organizations and Management." $A n$ International Journal Vol. 9 (4): 351-370.

\section{Sumber lain (Arsip Regulasi)}

Kepmen Kelautan dan Perikanan RI No. 38/KEPMEN/2009.

Kepmen Kelautan dan Perikanan RI No.5/KEPMENKP/2014.

\section{Sumber lain (laman internet):}

Kompas.com 24/12/2014. (http://kompas.com) Diakses tanggal 12 September 2018.

Program WWF Indonesia. (http://awsassets.wwf.or.id/downloads/m pa_for_fisheries_wwf_indonesia_2017.pdf)

Diakses tanggal 12 September 2018.

Program TNC Indonesia. (https://www.nature.or.id) Diakses tanggal 12 September 2018.

Masyarakat Lamalera Terus Jaga Tradisi Berburu Paus.

(https://nasional.kompas.com/read/2014/
12/24/10453681/Masyarakat.Lamalera.Te rus.Jaga.Tradisi.Berburu.Paus) Diakses tanggal 12 September 2018.

Seminar Ikan Paus di Lembata: Hadiah dari Tuhan dan Pemberian Leluhur. (http://kupang.tribunnews.com/2016/11/ 05/seminar-mamalia-paus-di-lembatahadiah-dari-tuhan-dan-pemberian-leluhur) Diakses tanggal 12 September 2018.

Kementerian Maritim Gelar Seminar Ikan Paus. (http://www.mediantt.com/kementerianmaritim-gelar-seminar-ikan-paus) Diakses tanggal 12 September 2018. 